\title{
Feminismo e configurações de gênero na guerrilha: perspectivas comparativas no Cone Sul, 1968-1985
}

Feminism and gender configurations in the guerrilla: comparative perspectives in the Southern Cone, 1968-1985

Cristina Scheibe Wolff ${ }^{1 \star}$

RESUMO

Este artigo pretende discutir as interfaces entre o feminismo de segunda onda e as configurações de gênero na guerrilha urbana durante o regime de Ditadura Militar, através de uma perspectiva comparativa, entre Brasil, Argentina e Uruguai. Para isso são utilizadas memórias e testemunhos de militantes e documentos produzidos pelas organizações de esquerda armada. Apesar de o feminismo não ser reconhecido como uma reivindicação importante pelos movimentos de esquerda da época, o número de militantes mulheres dessas organizações era muito maior que o de situações anteriores. As maneiras pelas quais as organizações lidavam com a presença de mulheres e utilizavam discursos de gênero também é problematizada e analisada de maneira comparativa.

Palavras-chave: ditadura millitar; guerrilha; gênero.

\section{ABSTRACT}

This work discusses the links between second-wave feminism and the gender configurations in urban guerrilla organizations during the so-called Military Dictatorship governments between 1964 and 1984, comparatively as between Brazil, Argentina and Uruguay, using memories and statements of the militants and documents of the armed leftwing organizations. Although feminism was not considered priority by these organizations at the time, the number of militant women was much larger than previously. The ways the organizations handled the presence of women, and the gender discourses used are also compared.

Keywords: military dictatorship; guerrilla; gender.

\footnotetext{
* Departamento de História - CFH - Universidade Federal de Santa Catarina (UFSC), Campus Universitário, Trindade. 88040-970 Florianópolis - SC - Brasil. cristiwolff@gmail.com.
} 
Durante as décadas de 1960 e 1970, a América do Sul viveu uma impressionante onda de Ditaduras Militares cujo discurso de legitimidade em parte se sustentava pelo combate aos movimentos de esquerda revolucionária que se espelhavam na Revolução Cubana, no Vietnã e na China para propor uma sociedade em moldes socialistas para os vários países onde se estruturaram. Che Guevara era citado em muitos folhetos e cartazes, os quais variavam seu discurso, mas mantinham um tom bastante semelhante, como neste, intitulado "Tarefas aos Revolucionários do Brasil":

Fica claro para nós que a única forma de luta contra a agressão imperialista é a luta armada revolucionária. Faz-se necessário abrir várias trincheiras de luta, com o intuito de dispersar, desgastar e derrubar o imperialismo.

No momento a palavra de ordem do "Internacionalismo Proletário" são palavras do Camarada Ernesto Che Guevara, quando diz que é preciso criar um, dois, três, muitos Vietnames. ${ }^{2}$

Esse período foi também marcado internacionalmente pela Revolução Sexual e pela chamada Segunda Onda do Movimento Feminista, e, não por acaso, nas organizações guerrilheiras o número de mulheres militantes ultrapassava em muito o número de mulheres que participavam dos Partidos tradicionais de esquerda em décadas anteriores. Nos grupos de guerrilha urbana do Brasil, Marcelo Ridenti calcula em torno de 18\% de mulheres, e sabemos que possivelmente eram mais já que o percentual é calculado com base nos processos movidos contra os militantes pela justiça. Segundo a ex-militante e socióloga Maria Lygia Quartim de Moraes, que militou na ALN como apoiadora, para as mulheres era mais fácil escapar da polícia, pois a não ser em casos notórios, era difícil acreditar que as mulheres seriam realmente guerrilheiras. Já no Movimento de Libertação Nacional (Tupamaros) do Uruguai, para o qual se estima um total de dez mil militantes, Ana Maria Araújo afirma a presença de um terço de mulheres na base do movimento. Entre os mortos e desaparecidos na Argentina, embora esta cifra não reflita necessariamente a proporção de mulheres nas organizações de luta armada, 30\% eram mulheres. ${ }^{3}$

Argentina, Brasil e Uruguai, assim como os outros países da América do Sul, viveram assim experiências de guerrilha urbana que mobilizaram um grupo considerável de homens e mulheres em sua grande maioria jovens, muitos dos quais eram estudantes universitários. Cada um desses países viveu contextos particulares com relação a tais movimentos armados. Cada uma 
das organizações tinha sua linha ideológica (que por vezes também variou no tempo), suas formas de organização e hierarquia, suas próprias posturas com relação à participação de mulheres e homens, recrutamento, regulamentos, posturas frente à clandestinidade, muitas especificidades. Isto, porém, não nos impede de traçar algumas linhas que cruzam grande parte dessas organizações, especialmente se tomamos as relações de gênero como guia. O desenho que emerge desse exercício de comparação é bastante regular, e é a partir dele que pretendo estabelecer a discussão que se segue.

Quando proponho comparar as relações de gênero nas diversas organizações de esquerda armadas que realizaram guerrilha urbana no Brasil, Argentina e Uruguai, não estou me referindo a simplesmente dar visibilidade às mulheres que participaram desses movimentos. Isso já foi feito por várias dessas mulheres a partir de suas memórias e relatos autobiográficos publicados, por jornalistas e por historiadores/as. ${ }^{4}$ Estou propondo analisar os discursos de gênero que atravessavam essas organizações. Esta proposta se baseia na compreensão do gênero como uma construção social, cultural e histórica, sempre relacional, e que define hierarquias e estratégias de poder, territórios e comportamentos para homens e mulheres. E também na compreensão dos discursos como práticas sociais, nas quais saber e poder se entrecruzam, configurando categorias sociais ao serem emitidas por instituições ou especialistas e também subjetividades, ao serem apropriados e emitidos pelos sujeitos. Afinal, como afirma Michel Foucault, "o discurso não é simplesmente aquilo que traduz as lutas ou os sistemas de dominação, mas é aquilo pelo qual e com o qual se luta, é o próprio poder de que procuramos assenhorear-nos". 5

Assim, para este artigo, não estamos procurando tanto as particularidades entre as organizações de esquerda e nos permitimos fazer uma leitura um tanto 'em bloco' delas. Isso é possível, pois, apesar de todas as diferenças, as organizações tiveram como protagonistas uma grande maioria de militantes provenientes de uma mesma geração, os jovens, muitos estudantes e de 'classe média', ou seja, não faziam parte da elite mais rica, nem das classes mais despossuídas.

Porém, considero importante esclarecer as principais organizações aqui referidas. Para o Brasil, neste artigo refiro-me a documentos da ALN (Ação Libertadora Nacional), formada em 1967, com a liderança acentuada de Carlos Marighela, dissidente do Partido Comunista Brasileiro. Também cito o MR8 (Movimento Revolucionário Oito de Outubro), organização proveniente do Movimento Estudantil, a partir da chamada Dissidência da Guanabara, e responsável, aliada à ALN, pelo célebre seqüestro do embaixador norte-ame- 
ricano, em 1969. Há referências também à VPR (Vanguarda Popular Revolucionária), e a uma sua ramificação, a VAR-Palmares (Vanguarda de Ação Revolucionária Palmares), formadas por ex-militares comunistas e estudantes, principalmente, e que atuaram mais em São Paulo. Ainda aparece no trabalho o PCdoB (Partido Comunista do Brasil), que organizou a Guerrilha do Araguaia no Norte do Brasil. Esses movimentos armados envolveram um número relativamente pequeno de pessoas e suas ações se localizaram especialmente em São Paulo e Rio de Janeiro, excetuando-se o Araguaia, e se deram entre 1968 e 1973.

$\mathrm{Na}$ Argentina, estou me referindo basicamente às duas maiores organizações armadas do período: primeiramente os Montoneros, braço armado da Juventude Peronista, muito influenciada pela Igreja Católica em sua formação e com uma paradoxal e complexa relação com Perón, e que atuou principalmente de 1970 a 1979. Os Montoneros foram uma organização militarizada, hierarquizada e que atuou na guerrilha urbana através de assaltos, seqüestros, execuções de torturadores e outros atos de "propaganda armada". A outra organização da Argentina que pesquisamos foi o ERP (Ejército Revolucionario del Pueblo), formado como extensão armada do PRT (Partido Revolucionario de los Trabajadores). O PRT era um partido trotskista, que em 1969 fez uma guinada ao leninismo e especialmente passou a adotar a teoria do Foco Revolucionário, baseada na experiência cubana e nos escritos de Che Guevara. Também muito militarizado e hierarquizado, embora menor que os Montoneros, o ERP proponha a internacionalização da luta revolucionária e procurava estabelecer relações com grupos armados de outros países, como o MIR chileno e os Tupamaros.

Para o Uruguai, nesse momento, estamos tomando o Movimento de Libertação Nacional (MLN) - Tupamaros. Formado a partir de 1965 com orientação marxista, a partir de grupos de diferentes orientações, como maoístas, anarquistas e socialistas, esse grupo promoveu a guerrilha urbana no Uruguai e foi tomado como um dos motivos para o golpe de Estado que lá ocorreu em 1973.

Embora a incorporação de mulheres nos grupos de esquerda armada não possa ser vista apenas como uma decorrência 'natural' do feminismo, é certo que não se pode pensar esses dois acontecimentos (o feminismo da Segunda Onda e a luta armada) como totalmente isolados um do outro. Para os grupos de esquerda, como nos fala Maria Amélia Almeida Telles, que era militante do PCdoB (que levou a efeito a Guerrilha do Araguaia), não se podia falar em feminismo, isso era "coisa de pequeno burguês". ${ }^{6} \mathrm{O}$ mesmo ocorria 
na Argentina e no Uruguai, como pudemos ver nas entrevistas realizadas até o momento. Alejandra Ciriza, ex-militante do PRT-ERP e atualmente militante feminista, em sua entrevista explica a atitude de seus companheiros e "responsáveis" diante de sua demanda de incluir questões relativas às mulheres nos folhetos e discussões da sua célula:

a resposta era que não, que era uma contradição secundária, e que eu ia ver que quando chegássemos ao socialismo, companheira, tem que ter paciência, esse era o argumento, e frente às atitudes machistas dos companheiros era a mesma coisa, que tínhamos que ter paciência, isso, estávamos num momento que não era socialismo e que era lógico que os companheiros eram machistas porque a sociedade era capitalista também é uma sociedade machista. ${ }^{7}$

Os vários relatos de ex-militantes, bem como textos escritos na época, também nos indicam que a militância nesses grupos era vista como algo 'viril', que exigia coragem e determinação, desprendimento e espírito de sacrifício, qualidades vistas em nossas sociedades como masculinas.

A honra, a coragem, a dignidade e a iniciativa, componentes de um imaginário de virilidade que se atualiza a cada época, são os valores apontados por Carlos Marighela, o líder e articulador da Ação Libertadora Nacional, uma das mais importantes organizações da esquerda armada no Brasil, morto em 1969, para justificar o uso da violência no contexto da Ditadura Militar. Na dedicatória do Mini-manual do Guerrilheiro Urbano, um de seus documentos mais conhecidos, ele afirmava:

Cada camarada que se opõe a ditadura militar e deseja resistir fazendo alguma coisa, mesmo pequena que a tarefa possa parecer. Eu desejo que todos que leram este manual e decidiram que não podem permanecer inativos, sigam as instruções e juntem-se a luta agora. Eu solicito isto porque, baixo qualquer teoria e qualquer circunstância, a obrigação de todo revolucionário é fazer a revolução ... Hoje, ser "violento" ou um "terrorista" é uma qualidade que enobrece qualquer pessoa honrada, porque é um ato digno de um revolucionário engajado na luta armada contra a vergonhosa ditadura militar e suas atrocidades. ${ }^{8}$

Para Marighela, nem todos podiam ser guerrilheiros. Aliás, a ALN era constituída com diversos grupos, dos quais os GTAs, Grupos Táticos Armados, eram a vanguarda. Havia os grupos de apoio, de infra-estrutura, que faziam tarefas diversas, e um projetado núcleo de inteligência. Em suas memó- 
rias, Ottoni Fernandes Júnior ${ }^{9}$ conta sobre seu recrutamento na ALN em entrevista com "Toledo", Joaquim Câmara Ferreira, o número 2 na hierarquia da organização enquanto viveu Carlos Marighela.

Depois de uma conversa amena para quebrar o gelo, contou o que sabia de mim e perguntou onde eu poderia ser mais útil, ressalvando que eu não deveria ir para o GTA, o núcleo de ação armada, especialmente por causa dos meus dois metros de altura. Soube do treinamento sobre explosivos e inteligência que eu fizera com um sargento do MNR que havia estado em Cuba.

- Todo mundo quer ir para o GTA, parece coisa de cow-boy. Mas temos muita deficiência na infra-estrutura, quase nada em termos de planejamento operacional, de análise de informações sobre o inimigo. Quero que você entre para um núcleo de inteligência que estamos criando, totalmente compartimentado do resto da organização, longe das ações e ligado diretamente a mim - falou com convicção. (p.206)

Segundo Fernandes Júnior, o núcleo de inteligência não chegou a efetivar-se, e ele acabou atuando no Grupo Tático Armado do Rio de Janeiro, até ser preso. Mas todos almejavam estar ali, de armas na mão. Uma das punições que um guerrilheiro recebia era não usar a arma por alguns dias. A arma era essencial, um verdadeiro fetiche para alguns, uma sensação de segurança e poder, como nos filmes de cowboys, para usar a expressão do autor. A ação armada era a proposta principal da ALN, segundo Fernandes:

O nome ALN surgiu no final de 1968 e logo os panfletos com a nova sigla eram deixados nas ações armadas organizadas em todo o país. A proposta básica da Aliança era de que a ação violenta revolucionária daria origem à organização. A repulsa à ditadura militar e a vontade de pegar em armas para derrubá-la deveriam ser os critérios básicos do recrutamento de militantes. Uma vez filiados à ALN, os grupos regionais tinham total autonomia para realizar as ações armadas contra a ditadura. Parecia-me que bastava ser contra a ditadura e ter coragem de pegar em armas para ganhar um lugar na Aliança. (p.231)

Esta proposta foi resumida para ele, quando estava sendo sondado pela organização, nas seguintes palavras de um seu conhecido, Fleury, não o conhecido torturador, mas o guerrilheiro Carlos Eduardo Pires Fleury: "E aí, Grandão? Quando você vai largar estes bundas-moles e assumir o seu lugar junto aos verdadeiros bolcheviques?" (p.230). 
Tratava-se de dar uma resposta viril à Ditadura Militar, mesmo que com organização quase impossível pela clandestinidade e pela repressão. E nesse sentido as qualidades e comportamentos ligados a virilidade, coragem, disciplina, abnegação, iniciativa e ação eram aquilo que se esperava desses novos heróis, que assim foram construídos desde aquele momento. Mesmo quando os jornais os tratavam como terroristas e subversivos, e a polícia os caçava nos becos das cidades ou nos lugares mais ermos do interior do Brasil, como se fez com Lamarca ou com os guerrilheiros do Araguaia, os regulamentos e os jornais das organizações de guerrilha, como o Venceremos! e O Guerrilheiro, já proclamavam os novos heróis da nação.

No número 2, anunciando sua volta, O Guerrilheiro, porta voz da ALN, proclamava, após descrever a morte de Toledo e de Marighela:

Que honraremos nossos heróis não só com a luta, como também com sua vingança. "Olho por olho, dente por dente" é, mais do que nunca um de nossos lemas. OU FICAR A PÁTRIA LIVRE OU MORRER PELO BRASIL. AÇÃO LIBERTADORA NACIONAL. Coordenação Nacional. 24 de outubro de $1970^{10}$

Em sua capa (Figura 1) a imagem mostrava uma mão forte e musculosa, que ergue o fuzil, supremo símbolo da ação revolucionária. Ensaiando uma interpretação imagética, poderíamos até dizer que a metralhadora e o fuzil

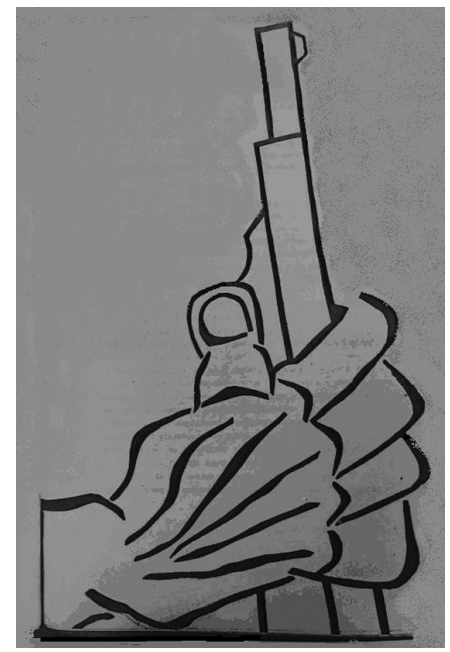

Figura 1 - Imagem da capa do jornal O Guerrilheiro, n.2, ALN. (Acervo: Arquivo Público do Estado de São Paulo, Documentos do Dops). 
são usados na propaganda guerrilheira como 'falos', que representam o poder - claro, neste caso não se trata de um poder instituído, mas de um poder que se quer constituir e que seria atingido com a ação revolucionária.

A ALN não era a única organização a se utilizar de componentes imagéticos da masculinidade em seus discursos para incitar e legitimar sua ação. Embora existam grandes diferenças entre as organizações, tanto no que tange a seu corpo ideológico, quanto em sua atuação política e armada, os discursos relativos às qualidades pretendidas para os militantes não variam muito.

Em uma publicação de 1969, possivelmente já preparatória para a guerrilha do Araguaia, por exemplo, o PCdoB estabelecia entre essas qualidades o heroísmo, o desprendimento, a devoção, a firmeza, a lealdade, a autoconfiança, a perseverança, a organização e a vigilância, além de serem 'homens':

O exército popular só poderá surgir no curso da própria luta e só dominará a arte de combater na própria guerra ... Guiar-se-á por uma disciplina consciente e seus componentes deverão ser exemplo de heroísmo, desprendimento e devoção à causa revolucionária ... A guerrilha precisa contar com homens firmes e de grande lealdade ao povo, com consciência revolucionária e confiança em si mesmos, que sejam perseverantes, tenham certo conhecimento de organização, capacidade de ligar-se às massas e vigilância contra a atividade desagregadora do inimigo. ${ }^{11}$ (grifos nossos)

O texto foi publicado sugestivamente por uma editora denominada Caramuru, personagem da literatura e da história brasileira que se impôs aos índios através de sua arma de fogo, tornando-se assim o 'senhor do trovão'.

Com todas as diferenças entre o contexto brasileiro, o argentino e o uruguaio, diferenças muito importantes mas que não nos cabe aprofundar neste momento, a esquerda - especialmente os grupos armados de esquerda - partilhava matrizes discursivas ${ }^{12}$ que passavam pela teoria política (marxismo, leninismo, trotskismo, maoísmo etc.) e pelas estratégias (guerra revolucionária prolongada, foquismo etc.), mas também por uma linguagem, modos de fazer, imagens. A linguagem da virilidade imputada à luta armada está presente nos mais diversos materiais das mais diversas organizações, seja nas ilustrações da revista Evita Montonera (Figura 2), ou nas célebres palavras de Jorge Ricardo Masetti, de que havia duas qualidades de pessoas: "Los que lutan y los que lloran":

Masetti, junto con Angel, Bengochea y otros hombres de esa talla nos enseñaron que en este país se podía y debía luchar, cuando casi nadie comprendía la necesidad 


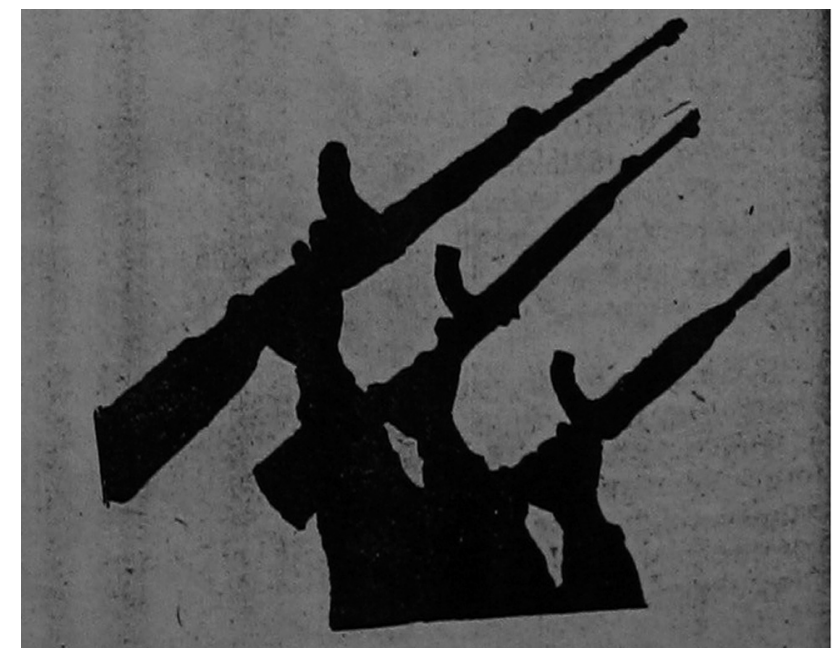

Figura 2 - Ilustração da revista Evita Montonera. Revista Oficial de Montoneros. Argentina, ano 1, n.1, jan.-fev. 1975. (Acervo do CeDinCi) p.22.

de la guerra revolucionaria. Ellos nos enseñaron que existen los que luchan y que existen los que lloran, ellos eligieron luchar. ${ }^{13}$

Assim colocava a questão o jornal do PRT-ERP, na Argentina, já em 1971, chamando para a luta armada aqueles "hombres de esa talla", aqueles que lutam, e não os que choram - afinal "homem não chora". Nesta mesma linha, parodiando Ernesto Che Guevara, esse mesmo jornal declarava em seu chamado à luta armada, após o Congresso que levou o Partido Revolucionário dos Trabalhadores à construção do Exército Revolucionário do Povo:

Sólo conspira contra el comienzo de esa lucha, la debilidad, la falta de decisión revolucionaria, de quienes diciéndose revolucionarios, esperan vaya a saber qué "condiciones" para cumplir con su deber: el deber de hacer la revolución. ${ }^{14}$

Esse discurso que associa a virilidade à guerra, e que para convocar para a luta armada buscava tocar o "orgulho masculino", nesse momento tocava a homens e mulheres. Uma das explicações que encontramos para isso é o lugar social onde estavam as mulheres nesse período. Apesar de não se dizerem feministas, de não existirem organizações que se reivindicassem feministas, na década de 1960, o número de mulheres que acediam ao mercado de traba- 
lho e, talvez mais significativamente para este contexto, o número de mulheres que começavam a freqüentar as universidades, nunca havia sido tão importante. Graciela Sapriza fala sobre isso citando números para o Uruguai:

Para las mujeres jóvenes de clase media "la política estaba en la calle" y sobre todo en las movilizaciones estudiantiles que comenzaron en 1967 y 1968, reflejo también del incremento de la matrícula femenina en la enseñanza media y superior. En el Censo universitario de 1963 las mujeres eran el 41\% del total de estudiantes, lo que dio comienzo a la "feminización" de la matrícula universitaria. ${ }^{15}$

Assim, a questão da participação das mulheres nesses movimentos armados, de sua provocação à ação, mesmo que centrada em um discurso normalmente dirigido aos homens, cheio de figuras de gênero, talvez possa ser compreendida se pensamos o gênero como descolado do corpo, como propõe Judith Butler, ao menos em algumas situações. ${ }^{16}$ Trata-se de identificarse, nesse momento, performaticamente mais como estudantes do que como mulheres. Nesse momento, mais do que mulheres, essas jovens eram estudantes, com toda a carga que se atribuía então aos estudantes universitários, vistos como futuro da nação. Cantava-se nas escolas do Brasil:

ESTUDANTE DO BRASIL

Letra: P. Barbosa e A. Taranto

Música: Raul Roulien

Estudante do Brasil! Tua missão é a maior missão:

Batalhar pela verdade, Impor a tua geração!

[Estribilho]

Marchar, marchar para a frente! Lutar incessantemente!

A vida iluminar, Idéias avançar!

E, assim, tornar bem maior, Com todo ardor juvenil:

A Raça, o Ouro, o esplendor Do nosso imenso Brasil!

Estudante do Brasil, Orgulho da Nação, tu hás de ser!

O Brasil almeja, ansioso, Que cumpras sempre o teu dever.

Com essa 'missão' de futuro que se atribuía a eles e elas, a de vanguarda ilustrada, e muitas vezes a de vanguarda revolucionária, o chamado do Che, os chamados das organizações de esquerda encontravam ressonância entre os estudantes, homens e mulheres. Após entrarem nas organizações, porém, pa- 
rece que o gênero se colava novamente ao corpo, nas práticas do cotidiano, nas tarefas atribuídas a cada militante, colocando os desafios para a incorporação de mulheres em uma 'guerra de guerrilhas' pensada como espaço masculino de atuação.

Fazer a revolução significava, nesses contextos, pegar em armas: "Hoy, en América Latina, lo que define el carácter revolucionario de una organización es su relación con la lucha armada", dizia o Suplemento de 1968 dos Tupamaros do Uruguai. Aqueles que portam as armas são assim vistos como os 'verdadeiros revolucionários', aqueles que lutam. Esta também era a opção da organização Peronista argentina Montoneros:

La alternativa sigue siendo hoy la liberación o la dependencia. Los Montoneros optamos por la liberación y lucharemos hasta dar la vida por ella ... Montonero es todo aquel que ama su patria y a su pueblo, que ama la paz y la justicia social, Montonero es todo hombre del pueblo que lucha desde su puesto, con las armas que tenga a su alcance por la JUSTICIA SOCIAL, la INDEPENDENCIA ECONOMICA $y$ la SOBERANIA POLITICA. ${ }^{17}$

No símbolo escolhido, a sempre presente arma, justaposta a uma lança para lembrar os antigos amotinados das conhecidas Montoneras, rebeliões do passado, de cunho nacionalista (Figura 3).

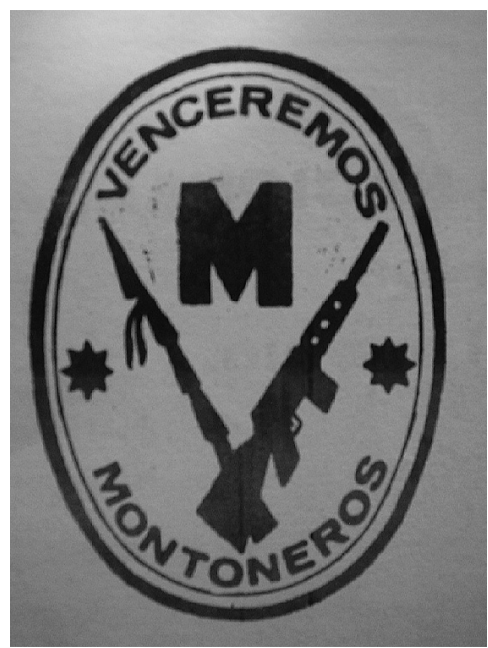

Figura 3 - Símbolo dos Montoneros.

Retirado de El Montonero, n.12, 17.10.1976; Acervo CeDinCi. 
Ainda nos falta explorar melhor na documentação levantada para esta pesquisa o discurso relacionado à participação feminina nas organizações de esquerda. Sendo uma das grandes matrizes discursivas, os textos de Ernesto Che Guevara são paradigmáticos para entender as posturas tomadas. Em sua obra A guerra de guerrilha, ele dedica duas páginas ao "Papel da Mulher" nas quais afirma ser este extremamente importante; embora mais fraca, ela é resistente e pode portar armas e combater ao lado dos homens, embora seu papel mais importante seja o de servir de agente de ligação e mensageira, pois ela chama menos atenção dos soldados inimigos e pode passar mais despercebida. Além disso, ele afirma que as mulheres podem servir como cozinheiras, professoras, costureiras e enfermeiras, "com uma doçura infinitamente superior à de seu rude companheiro de armas". Sobre isso comenta Ana Maria Araújo:

As concepções do Che são duras de admitir para uma mulher e uma militante política: encontramos aí a reprodução da ideologia dominante, do papel tradicional que ela designou às mulheres. Se o Che Guevara escreveu o que escreveu, isto não é mais que uma prova a mais da força profunda, inconsciente e enraizada do machismo, mesmo entre os maiores revolucionários. ${ }^{18}$

Notei na documentação consultada até o momento que há significativa diferença entre as organizações dos vários países pesquisados diante dessa questão: na Argentina e no Uruguai é mais comum encontrarmos textos e imagens que coloquem homens e mulheres como sujeitos da luta armada. Especialmente, é possível notar no material impresso pelos Tupamaros, como o jornal El Tupamaro, a presença de imagens e nomes de mulheres, embora de maneira minoritária. Se analisamos o material de Montoneros e do ERP também aparecem algumas mulheres, especialmente quando se trata de fotos de manifestações e atividades como pichações. Porém, se analisamos as fotos individuais publicadas, os rostos masculinos dos 'líderes' são quase onipresentes. Algumas mulheres aparecem por sua liderança, ou, quando morriam, como forma de homenagem póstuma. No Brasil, a palavra 'homens' é a mais comum para designar esse sujeito, sempre no masculino, mas há exceções. Esse é ainda um caminho a ser trilhado na pesquisa, mas já podemos ouvir o que têm a nos dizer as mulheres que participaram das organizações.

Ao ser questionado em entrevista sobre o papel das mulheres na guerrilha, Urbano, um dos responsáveis pela direção do Movimiento de Liberación Nacional - Tupamaros do Uruguai, respondeu: "Primero te diría que nunca es más igual una mujer a un hombre que detrás de una pistola 45”. Entretanto, colocar-se atrás de uma arma não era uma tarefa tão simples assim para uma mulher. Segundo Ana Maria Araújo, que militou nessa organização, "A parti- 
cipação das mulheres na luta armada quebrou o mito de sua passividade e de sua não-violência, mas na organização política onde eu estava, nós, as mulheres, continuamos a ser passivas ao nível da teoria e da elaboração política". ${ }^{19}$ Assim, se eventualmente uma mulher atrás de uma arma podia estar em relação de igualdade com seus companheiros, isso nem sempre acontecia nas reuniões do grupo, nas quais a palavra masculina muitas vezes tinha mais peso - o peso da teoria -, e na hierarquia do grupo. Várias entrevistadas referem-se a que os cargos de responsabilidade na hierarquia Tupamara eram mais acessíveis aos homens.

$\mathrm{Na}$ Argentina a situação era semelhante, mas algumas particularidades podem ser destacadas. A principal e mais numerosa das organizações de luta armada, Montoneros, era ligada ao Peronismo, e portanto à figura bastante mistificada de Eva Perón. Embora fosse uma figura feminina ligada ao poder, Evita era ao mesmo tempo assimilada a uma imagem muito tradicional da mulher: ela era a mãe, aquela que cuidava de seus filhos, o povo argentino, já que era a esposa do pai, Perón. ${ }^{20}$ Nos depoimentos recolhidos pela jornalista Marta Diana em seu livro Mujeres Guerrilleras, o que mais chamou minha atenção foi o aspecto hierarquizado e moralista da organização Montoneros. Nessa hierarquia parecia haver lugar para mulheres, especialmente como responsáveis por novos militantes incorporados à organização, porém estas estavam normalmente subordinadas aos chefes, geralmente homens. Na medida em que se integram na organização, as mulheres entrevistadas acabam por também integrarem casais, quando não entram mesmo na organização já como companheiras de um militante. Neste caso toda uma conduta era esperada dos casais, o que incluía mesmo punições para adultérios e outros comportamentos que saíssem da 'linha' traçada. No Código de Justiça Penal Revolucionária, publicado em 4 de outubro de 1975, lia-se o artigo n. 16: "Deslealtad. Incurren en este delito quienes tengan relaciones sexuales al margen de la pareja constituida, son responsables los dos términos de esa relación aún cuando uno solo de ellos tenga pareja constituida". ${ }^{21}$

O PRT-ERP apresentava outra perspectiva sobre essa questão. O texto Moral y Proletarización, atribuído a Julio Parra, apresentava uma crítica muito forte ao individualismo e propunha uma moral para "o novo homem" que enfatizava o coletivo e o social ao invés do individual, e colocava o comportamento dos guerrilheiros como questão central a ser pensada pela organização. ${ }^{22}$ Uma das questões mais polêmicas sobre esse documento relacionava-se aos filhos dos guerrilheiros. O partido propunha que as crianças fossem assumidas coletivamente pelas células, deslocando assim essa maneira 'burguesa' de tratar as crianças e, ao mesmo tempo, nesses tempos tão perigosos, tinha a idéia de tranqüilizar os pais com relação a seus filhos. Se 'caía', se era 
preso, o casal sabia que seus filhos seriam cuidados pelos companheiros. Uma militante do ERP que não quis se identificar, confrontada com a situação de ter um filho, deixou a militância, contra a vontade de seu marido. Apesar da orientação da organização, "sentia que não podia deixar meu filho, que era demais...."

Outro aspecto que os depoimentos destacam é a questão da maternidade. Nas trajetórias das guerrilheiras esse é um tema que aparece de maneira constante. Aparentemente a organização Montoneros tinha um discurso natalista, tal como no Uruguai: as crianças eram vistas como guerrilheiros potenciais; quanto mais crianças nascessem, melhor. Porém, ser guerrilheira e mãe, numa vida clandestina, era uma tarefa difícil, que impunha escolhas e também uma reflexão sobre os papéis de gênero. Afinal, isso se colocava para as mulheres, raramente para os homens. Não se via nenhuma impossibilidade em ser guerrilheiro e pai. O depoimento de Frida é muito claro:

Recluida en un departamento con dos bebés yo, que había sido militante de primera línea, que había armado mis propias cosas, que había jugado mis propios papeles, me encontré lavando pañales mientras mi compañero se iba a la mañana y volvía a la noche por que tenía cita tras cita y numerosas actividades. ${ }^{23}$

No Brasil os depoimentos quanto às atividades das mulheres nas organizações de luta armada têm um teor muito semelhante a esse, evocado na Argentina. Aqui as organizações foram muito diversificadas, e muitas vezes a hierarquização e a militarização eram aparentemente menos acentuadas que na Argentina e no Uruguai. Algumas mulheres chegaram a ocupar postos no comando central, como foi o caso de Vera Silvia Magalhães, que, em entrevista a Luiz Maklouf Carvalho, por exemplo, fala de sua situação como uma das poucas líderes mulheres da Dissidência da Guanabara, depois, MR8: "Eu era a única mulher no meio de sete homens. Fiz um puta esforço para chegar lá. A minha militância política foi uma batalha, porque, além de tudo, havia o preconceito machista". ${ }^{24}$

Nas memórias, o problema exposto pelas antigas militantes parece ser o mesmo. Vânia, uma das depoentes da coletânea Memórias das mulheres no exílio, publicada em 1978, apresenta a questão desta maneira:

Não é que as mulheres tivessem tarefas diferentes dos homens, não. Era um processo natural: no começo éramos todos iguais, mas no fim as mulheres ficavam no movimento estudantil. Nós participávamos das ações, mas os treinamentos para as mulheres eram menos intensivos. E além do mais, tínhamos a 
tarefa fundamental de manter as casas. Isso não estava escrito em parte nenhuma, mas na prática todas as mulheres faziam isso. Em relação às tarefas domésticas, todos os homens eram meio domésticos, lavavam pratos. Não era grande desdouro, não era essa a questão. Naquele esquema isto fazia parte do espírito revolucionário. A mulher deixou de ser virgem, o homem deixou de ser macho, lava pratos, faz comida, é bom cozinheiro. Eu acho que isso não era o fundamental. As análises, as grandes análises, a estratégia e a tática, isso era o que importava. E isso eram eles que faziam. ${ }^{25}$

A figura da mulher revolucionária e guerreira, capaz de pegar em armas e bater-se corajosamente, muitas vezes ligada a um companheiro, não é estranha ao imaginário latino-americano. Anita Garibaldi, por exemplo, nascida no sul do Brasil, aparece em muitos monumentos e nos livros de história como "a heroína dos dois mundos", por ter "seguido" seu companheiro Giuseppe Garibaldi nas revoluções nas quais este lutou no Brasil, no Uruguai e na sua Itália natal. ${ }^{26}$ Também temos no Brasil o caso de Olga Benário Prestes e de algumas outras. As mulheres que se fizeram guerrilheiras nas décadas de 1960 e 1970 na América do Sul, no entanto, como demonstram suas memórias, nem sempre se contentaram com o papel da companheira, fiel seguidora, elemento de ligação, provedora e enfermeira dos homens. Para isso muitas vezes tiveram de enfrentar as representações de gênero, as quais exigiam também uma imagem diferente dessas mulheres. Afinal, se o grande espelho do guerrilheiro era Che Guevara, com seu ar altaneiro e sério, seu charuto cubano, barba e uniforme verde-oliva, o olhar crítico e suas palavras de violência e ternura - hay que endurecerse pero sin perder la ternura jamás -, como aquelas mulheres iam se reconhecer? A imagem viril do Che era propícia aos jovens estudantes, alguns de origem nas classes trabalhadoras, que contestavam seus pais, seus professores, e mesmo os dirigentes dos partidos tradicionais de esquerda como o Partido Comunista Brasileiro, formando novas organizações. Ser guerrilheiro era sim ser 'macho', era assumir uma postura ativa, contestadora, era assumir a violência como forma de resolver o problema. Já vimos como palavras como coragem, honra, orgulho, força, resistência e dignidade aparecem nos documentos das organizações dos três países analisados.

Essas palavras, como nos ensina Judith Butler, constroem subjetividades de gênero ou que têm referência no gênero. O militante tinha de perder tantas coisas ao cair na clandestinidade e escolher o caminho da luta armada: perdia seu nome, sua família, seus amigos de infância, muitas vezes era deslocado para outra cidade, perdia profissão, trabalho, lazeres, manias, tudo em nome da revolução. Mas não perdia seu gênero, e este ao que parece era reforçado no caso dos homens. Para as mulheres a história era muito diferente. 
Para começar, mesmo que o poema do uruguaio Daniel Viglietti a chame de mujer entera, a guerrilheira perde muitas vezes o seu gênero, para reconstruílo em outros parâmetros é certo, mas trata-se de uma grande mudança necessária à sua aceitação como 'companheira'.

Nelida Auger, mais conhecida como "Pola”, conta a Marta Diana como foi sua admissão no PRT (Partido Revolucionario de los Trabajadores). Em seu primeiro encontro com o responsável, sua entrada foi protelada: "Llegué puntual. Diecisiete años, largo pelo lacio hasta la cintura, diminuta minifalda, blusa escotada, y un corazón que latía emocionado por la inminencia del encuentro con el 'Responsable'". Depois desse encontro, do qual saiu tão decepcionada, o segundo envolveu uma outra preparação: "Llegué primero. Pelo corto como hombre, zapatillas, blue jeans, camisa de hombre" (Diana, 1997, p.88). Teve de apresentar-se, pois o responsável não a reconheceu. Além de uma mudança na aparência, Pola mudara sua atitude: apresentou-se, mostrou-se segura de si, impôs-se. Aí foi aceita. Da mesma maneira Dulce Maia, a "Judith", militante da Vanguarda Popular Revolucionária, no Brasil, foi qualificada várias vezes como um "homem", "macho", tanto por companheiros de organização quanto pelos torturadores, surpresos com sua coragem e resistência (Carvalho, 1998, p.56).Aparentemente ser viril, ser ativo, corajoso, capaz de grandes sacrifícios por um ideal, manejar armas, ou seja, ser um "verdadeiro bolchevique", não era algo impossível para mulheres. Mas elas teriam de se provar capazes, talvez de maneira um pouco mais dura que seus companheiros homens, para quem a virilidade estaria já incorporada como um atributo de gênero. As mulheres teriam de se apropriar de atributos do gênero masculino para se tornarem verdadeiras revolucionárias, como Marta, mãe de Clemente, que merecia a admiração do cubano "Orloff": "Quando encontrar com Marta mande um grande abraço e minha admiração, ela é uma mulher que tem cojones" (Paz, 1997, p.113).

Se por um lado podemos falar de certa 'influência' do feminismo nas organizações de esquerda armada a partir da admissão das mulheres nessas organizações, e de sua efetiva participação, muitas vezes de armas na mão, nos eventos, além de sua prisão, tortura e desaparecimento, por outro lado a impressão que temos ao ler os relatos ou ouvir os testemunhos das pessoas entrevistadas é que uma 'consciência feminista' apenas se deu nessas mulheres num momento posterior. Como se o contato com os movimentos e literatura feministas no exílio ou após 1975, com o Ano da Mulher instituído pela Organização das Nações Unidas, ${ }^{27}$ desse a tais mulheres palavras para expressar o que antes seria um sentimento difuso diante daquilo que lhes acontecia no cotidiano. $^{28}$

Esse cotidiano variava muito de organização a organização, e até mesmo 
de uma célula a outra. Nora Llames contou-me sobre sua experiência de Montonera, dizendo que se sentiam realmente como "homens e mulheres novos", como propunha o Che, e que em sua célula compartilhavam tudo. Lembrouse, porém, de um episódio em que um chefe da organização fazia uma visita a uma casa, e de maneira um tanto grosseira disse a uma companheira que lhe trouxesse comida, pressupondo ser esse o seu papel como mulher naquela casa. ${ }^{29}$ Já Ana Maria Araújo, uma Tupamara, em seu livro Tupamaras: Les femmes de l'Uruguay, indica um ressentimento maior perante a organização da qual participava, próximo do encontrado no discurso de algumas brasileiras já citadas. ${ }^{30}$ Até o momento, quando lemos as listas de dirigentes, ou mesmo as assinaturas dos documentos publicados ou as listas de heróis guerrilheiros combatentes nos jornais das organizações de esquerda armada do Cone Sul, a impressão é realmente de que embora fossem aceitas e muito bem-vindas para as tarefas, às mulheres não cabia escrever e organizar, pois estes ainda eram espaços reservados aos homens.

O feminismo pode não ter sido admitido e explicitado entre os movimentos de esquerda armada no Cone Sul. Era visto, afinal, pelos militantes homens e mulheres, como algo "pequeno-burguês", uma reivindicação menor de mulheres de classe média que não tinham "mais o que fazer". Porém algumas relações precisam ser feitas. Muitas das jovens guerrilheiras e militantes, a partir do exílio ou a partir de suas trajetórias posteriores, por exemplo, com militância em movimentos pelos Direitos Humanos, geralmente protagonizados por mulheres, tornaram-se feministas. O número e a relevância das militantes mulheres na Nova Esquerda foram muito importantes se levamos em conta os números de mulheres militantes de partidos tradicionais, de esquerda ou de direita. Embora os grupos de consciência, os periódicos feministas, as casas de mulheres e outras expressões do feminismo de segunda onda surgissem em paralelo com os movimentos armados de esquerda ou como sua conseqüência, tanto no Brasil como na Argentina e no Uruguai, o próprio fato de as mulheres estarem neste momento nas Universidades, em números nunca antes experimentados, e de se sentirem convocadas elas também pelo discurso tão genderizado no masculino para a luta social, colocando-se assim numa relação de igualdade com seus companheiros homens, já expressa uma mudança importante. Não é à toa que tenham sentido tantas vezes a discriminação, construindo pouco a pouco um ressentimento com relação a seus companheiros que foi crescendo e assumindo importante papel na construção do feminismo pós-ditadura. Disse-me uma ex-militante de Direitos Humanos, então exilada nos Estados Unidos, que, sendo responsável pelo escritório da Anistia Internacional, era vista por seus companheiros como um homem. Segundo ela, estar em uma posição de poder fazia da militante "um homem". Diziam-lhe: 
"venha para a reunião, companheira, enquanto as mulheres fazem as empanadas". O poder, nesse caso, masculinizava, propiciava uma ascensão de status. É assim que mais uma vez podemos dizer: gênero é poder.

\section{NOTAS}

${ }^{1}$ Este texto é resultado do projeto "Relações de gênero na luta da esquerda armada: perspectivas comparativas no Cone Sul", que conta com o apoio do CNPq através de bolsa de produtividade em pesquisa e de auxílio pesquisa. Também resulta da colaboração com o projeto "Feminismos e movimentos sociais de resistência às ditaduras no Cone Sul: uma história comparativa (1960-1980)", coordenado por Joana Maria Pedro e também apoiado pelo CNPq. Contou com a colaboração, na coleta e sistematização dos dados, das bolsistas de iniciação científica Vivian Barbosa Moretti e Margareth Victória Kolb, e da estagiária Sabrina Fernandes de Melo.

${ }^{2}$ Tarefas aos Revolucionários do Brasil. (Documento mimeografado apreendido pela polícia política). Arquivo Edgard Leuenroth, Fundo Brasil: Nunca Mais - Anexos, número 183. (fotos 118-125).

${ }^{3}$ Para o Brasil, ver RIDENTI, Marcelo. O fantasma da revolução brasileira. São Paulo: Ed. Unesp, 1993, p.198. Para Argentina e Uruguai, ver: ANDÚJAR, Andrea; D’ANTONIO, Débora; DOMÍNGUEZ, Nora et al. (Org.). Historia, género y politica en los '70. Buenos Aires: Feminaria, 2005. A entrevista com Maria Lygia Quartim de Moraes foi concedida a Joana Maria Pedro e Cristina Scheibe Wolff, no dia 28.03.2007, em Florianópolis. Para os outros dados citados, cf. ARAUJO, Ana Maria. Tupamaras. Des femmes de l'Uruguay. Paris: Des Femmes, 1980, e CAPDEVILA, Luc. Genre et armées d'Amérique Latine. Clio. Histoire, Femmes et Societés, n.20, Toulouse: Presses Universitaires du Mirail, 2004, p.147-168, p.158.

${ }^{4}$ Por ejemplo, ver: DIANA, Marta. Mujeres guerrilleras: sus testimonios en la militancia de los setenta. Buenos Aires: Booket, 2006; ARAUJO, Ana Maria. Tupamaras. Des femmes de l'Uruguay, 1980, cit.; CARVALHO, Luiz Maklouf. Mulheres que foram à luta armada. São Paulo: Globo, 1998; COLLING, Ana Maria. A resistência da mulher à ditadura militar no Brasil. Rio de Janeiro: Record; Rosa dos tempos, 1997; ZOTTELE, Ingrid et al. Femmes et Dictature. tre chilienne sous Pinochet. Récits recueillis et présentés par Catherine BLAYA. Paris: ESF, 2000; e TALLER DE GÉNERO Y MEMORIA - ex Presas Políticas. Memorias para armar (3v.). Montevideo: Editorial Senda. 2001.

${ }^{5}$ FOUCAULT, Michel. A ordem do discurso. (L'Ordre du discours, Leçon inaugurale au Collège de France prononcée le 2 déc. 1970, Paris: Gallimard, 1971.) Trad. Edmundo Cordeiro e António Bento. Disponível em www.unb.br/fe/tef/filoesco/foucault/biblio.html; acesso em: 31.05.2007. Sobre a perspectiva de gênero cf. SCOTT, Joan. Gênero: uma categoria útil de análise histórica. Educação e Realidade, Porto Alegre, v.16, n.2, p.5-22, jul.-dez. 1990; NICHOLSON, Linda. "Interpretando o gênero". Estudos Feministas, Florianópolis: 
CFH/CCE/UFSC, v.8, n.2, 2000, p.9-41; PEDRO, Joana Maria. Traduzindo o debate: o uso da categoria gênero na pesquisa histórica. História, São Paulo, v.24, n.1, p.77-98, 2005.

${ }^{6}$ Entrevista realizada por Joana Maria Pedro, 24.08.2005, gentilmente cedida para uso nesta pesquisa.

${ }^{7}$ Entrevista com Alejandra Ciriza (A) e Nora Llavez (N), por Cristina Scheibe Wolff (C), em 27.10.2006 em Vila Giardino, Córdoba, Argentina. Transcr. e trad.: Veridiana Alves; rev.: Iarssan Danbros.

${ }^{8}$ MARIGHELA, Carlos. Mini-manual do guerrilheiro urbano (junho de 1969). Disponível em: www.emilianojose.com.br/marighela/marighela_manual.htm; acesso em: 4.04.2005.

${ }^{9}$ FERNANDES JUNIOR, Ottoni. O baú do guerrilheiro. Memórias da luta armada urbana no Brasil. Rio de Janeiro: Record, 2004.

${ }^{10}$ Acervo: Arquivo Edgard Leuenroth - Fundo: Brasil: Nunca Mais - Anexos. Identificação do CD: Foto 091.jpg. Título do Documento: O Guerrilheiro, n.2, 1970.

${ }^{11}$ Guerra Popular. Caminho da luta armada no Brasil. Rio de Janeiro: Caramuru, 1969. Cópia datilográfica. Publicado pelo Comitê Central do PCdoB. Fundo Deops, Arquivo Público do Estado de São Paulo. Foto DSCF0089.

${ }^{12}$ Eder Sader, em um livro clássico de análise dos movimentos sociais no Brasil, utilizou esta categoria "matriz discursiva" para mostrar elementos comuns em vários dos movimentos sociais surgidos a partir da década de 1980. Ela me parece adequada também para uma análise que procura comparar diversas organizações de esquerda que em contextos diferenciados partilhavam livros, manuais, imagens, idéias e discursos. SADER, Eder. Quando novos personagens entraram em cena. Rio de Janeiro: Paz e Terra, 1988.

${ }^{13}$ El Combatiente, n.51, ene. 1971. Acervo: CeDinCi, Foto: PA206042 (Jornal do PRT, Argentina).

${ }^{14}$ El Combatiente, ano 1, n.1, 6 mar. 1968. Acervo: CeDinCi, Foto PA206025.

${ }^{15}$ SAPRIZA, Graciela. Memórias del cuerpo. In: ANDÚJAR, Andrea; D’ANTONIO, Débora; DOMÍNGUEZ, Nora et al. (Org.). Historia, género y politica en los '70. Buenos Aires: Feminaria, 2005, p.39-60, p.42.

${ }^{16}$ BUTLER, Judith. Problemas de gênero. Feminismo e subversão da identidade. Rio de Janeiro: Civilização Brasileira, 2003. p.20.

${ }^{17}$ El Partido Montonero y el Movimiento Montonero. Mario Eduardo Firmenich, Horacio Mendizábal, Fernando Vaca Narvaja, por la Conducción Nacional y el Secretariado Nacional del Partido Montonero. El Montonero, n.12, 17.10.1976, p.15-6. Acervo CeDinCi. O documento sobre os Tupamaros está disponível na web www.chasque.net/mlnweb/documentos/documento1.htm; acesso em: 1.06.2007.

${ }^{18}$ ARAUJO, Ana Maria. Tupamaras. Des femmes de l'Uruguay, 1980, cit., p.133. "Les conceptions du Che sont durs à admettre pour une femme et une militante politique: on y retrouve la reproduction de l'idéologie dominante, du rôle traditionnel qu'elle a assigné aux fem- 
mes. Si le Che Guevara a écrit ce qu'il a écrit, cela n'est qu'une preuve de plus de la force profonde, inconsciente et enracinée du machisme, même chez les plus grands révolutionnaires". A citação anterior está em GUEVARA, Ernesto Che. La guerre de guérilla. In: Textes militaires. Paris: La Découverte, 2001. (1962), p.26-133. p.96 (tradução minha).

19 "La participation des femmes à la lutte armée a brisé le mythe de leur passivité et de leur non-violence, mais dans l'organisation politique où j'étais, nous, les femmes, continuions à être passives au niveau de la théorie et de l'élaboration politique." ARAUJO, Ana Maria, cit., p.22.

${ }^{20}$ Estou me baseando em parte em observações de Luc Capdevila e em sua discussão no artigo já citado. Ver também FISHER, Jo. Out of the shadows: women, resistence and politics in South America. London: Latin American Bureau, 1993.

${ }^{21}$ Documento publicado em Lucha Armada en la Argentina, Buenos Aires, año 3, n.8, 2007, p.124-127, p.125. Ver também DIANA, Marta. Mujeres guerrilleras. La militância de los setenta en el testimonio de sus protagonistas femininas. 2.ed. Buenos Aires: Planeta, 1997. (col. Espejo de la Argentina).

${ }^{22}$ Ver POZZI, Pablo. "Por las sendas argentinas": el PRT-ERP la guerrilla marxista. Buenos Aires: Imago Mundi, 2004; e OBERTI, Alejandra. La moral según los revolucionarios. Políticas de la Memoria, Buenos Aires, n.5, 2004/2005, p.77-84.

${ }^{23}$ Frida. In: DIANA, Marta, 1997, cit., p.60.

${ }^{24}$ CARVALHO, 1998, cit., p.172. Vera Sílvia Magalhães integrava a Direção Geral da Dissidência da Guanabara.

25 "Vânia" em COSTA, Albertina de Oliveira et al. (Ed.). Memórias das mulheres do exílio. Rio de Janeiro: Paz e Terra, 1980. p.113. (grifos meus).

${ }^{26}$ Interessante sobre esse aspecto é o livro: SALAS, Elizabeth. Soldaderas in the mexican military. Austin: University of Texas Press, 1990.

${ }^{27}$ Sobre isto ver PEDRO, Joana Maria. Narrativas fundadoras do feminismo: poderes e conflitos (1970-1978). Revista Brasileira de História, São Paulo, n.52, dez. 2006, p.249-272.

${ }^{28}$ Ver sobre esta questão WOLFF, Cristina Scheibe. Féminisme et lutte armée: un regard à partir de l'exil. Apresentado ao Colloque International Memoires, histoires, imaginaires de l'exil brésilien en France. Nanterre/Paris, Université Paris X, nov. 2005. (Há perspectiva de publicação próxima em livro).

${ }^{29}$ Entrevista com Alejandra Ciriza (A) e Nora Llavez (N), por Cristina Scheibe Wolff (C), em 27.10.2006 em Vila Giardino, Córdoba, Argentina. Transcr. e trad.: Veridiana Alves; rev.: Iarssan Danbros.

${ }^{30}$ ARAUJO, Ana Maria. Tupamaras. Des femmes de l'Uruguay, 1980, cit., p.22, tradução minha.

Artigo recebido em novembro de 2007. Aprovado em dezembro de 2007. 